Originalni naučni rad

UDK: $66.017 / .018: 538.945$

Primljen: 30. 3. 2017.

544.223 .22

Revidirana verzija: 16. 11. 2017.

621.315 .5

Prihvaćen: 6. 12.2017.

doi: $10.5937 /$ nabepo22-13580

\title{
PROCESS OF PHONON DIFFUSION THROUGH CRYSTALLINE STRUCTURES
}

\author{
Jovan P. Šetrajčić ${ }^{1}$ \\ Faculty of Sciences, University of Novi Sad \\ Stevo K. Jaćimovski ${ }^{2}$ \\ Academy of Criminalistic and Police Studies, Belgrade \\ Dušan I. Ilić ${ }^{3}$ \\ Faculty of Technical Sciences, University of Novi Sad

\begin{abstract}
Instead of usual approach, applying displacement-displacement Green's functions, the momentum-momentum Green's functions will be used to calculate the diffusion tensor. These functions enter into Kubo's formula defining diffusion properties of the system. Calculation of the diffusion tensor requires solving of the system of difference equations. It is shown that the elements of the diffusion tensor express discrete behaviour of the dispersion law of elementary excitations and, more important - that they are temperature independent.
\end{abstract}

Keywords: crystalline structures, phonons, Green's functions, diffusion tensor.

1 Academician, Full Professor, jovan.setrajcic@df.uns.ac.rs

2 Associate Professor, jacimovskis@gmail.com

3 Assistant Professor, dusilic69@gmail.com 


\section{Introduction}

The most important task of statistical physics is finding the average values of dynamic quantities [1-3]. For the quantity $A(x, t)$ the average value is defined as:

$$
\langle\hat{A}(x, t)\rangle_{t}=\mathfrak{\Phi}\left\langle\hat{A}(x, t) \hat{\rho}_{t}\right\rangle
$$

where:

$$
\hat{\rho}_{t}=\mathrm{e}^{-i \hat{H}_{0} t / \hbar} \hat{S}\left(t, t_{0}\right) \mathrm{e}^{i \hat{H}_{0} t / \hbar}
$$

is the nonequilibrium static operator, while $\rho_{0}$ - is equilibrium static operator. ${ }^{4}$ If (1) is written as (2) and when two cyclic permutations of the operator are performed [7-9], one obtains:

that is:

$$
\boldsymbol{\mathcal { S }}\left\langle\hat{A}(x, t) \hat{\rho}_{t}\right\rangle=\boldsymbol{\mathcal { S }}\left\{\hat{S}^{-1}\left(t, t_{0}\right) \mathrm{e}^{i \hat{H}_{0} t / \hbar} \hat{A}(x, t) \mathrm{e}^{-i \hat{H}_{0} t / \hbar} \hat{S}\left(t, t_{0}\right) \hat{\rho}_{0}\right\},
$$

$$
\langle\hat{A}(x, t)\rangle_{t}=\left\langle\hat{S}^{-1}\left(t, t_{0}\right) A(x, t) \hat{S}\left(t, t_{0}\right)\right\rangle_{0},
$$

where:

$$
A(x, t)=\exp \left(-\frac{H_{0} t}{i \hbar}\right) \hat{A}(x, t) \exp \left(\frac{H_{0} t}{i \hbar}\right),
$$

is the Schrödinger operator $A(x, t)$, written in interaction representation. With $\langle\cdots\rangle_{\text {t }}$ the nonequilibrium average values are denoted while with $\langle\cdots\rangle_{0}$ 0 the equilibrium average values are denoted. $\hat{S}\left(t, t_{0}\right)$ is the unitary operator, the so called scattering matrix:

$$
\hat{S}\left(t, t_{0}\right)=\hat{T} \exp \left[\frac{1}{i \hbar} \int_{t_{0}}^{t} d^{\prime} \hat{W}\left(t^{\prime}\right)\right] .
$$

If $\hat{S}$-matrix is linearly expanded and if we limit ourselves only to the first two members of that expansion, the following is obtained for the $\hat{W}(t)$ :

4 For calculating the non-equilibrium average values it is the most convenient to use the equilibrium operator of the great canonic ensemble [4-6]: $\hat{\rho}_{0}=\mathrm{e}^{\left(\Omega+\mu \hat{N}_{0}-\hat{N}_{0}\right)}$, because the great canonic distribution is the most general one (it includes the laws of maintaining the average energy and average number of particles).

[2] NBP • Žurnal za kriminalistiku i pravo 
\[ \hat{S}^{ \pm 1}\left(t, t_{0}\right)=1 \pm \frac{\hat{T}}{i \hbar} \int_{t_{0}}^{t} d^{\prime} \hat{W}\left(t^{\prime}\right) \]
thus following
$\langle\hat{A}(x, t)\rangle_{t}=\langle A(x, t)\rangle_{0}+\frac{1}{i \hbar} \int_{t_{0}}^{t} d^{\prime}\left\langle A(x, t) \hat{T} \hat{W}\left(t^{\prime}\right)-\hat{T} \hat{W}\left(t^{\prime}\right) A(x, t)\right\rangle_{0}$.

Since the chronological operator $\hat{T}$ affects only $\hat{W}\left(t^{\prime}\right)$ it does not have to be written in the above equation. The written equation is valid only for $t>t^{\prime}$, thus in front of the resulting operators $\hat{A}$ and $\hat{W}$ Heaviside's step-function is introduced $\Theta\left(t-t^{\prime}\right)$, defined in the following way:

$$
\Theta\left(t-t^{\prime}\right)= \begin{cases}1 & t>t^{\prime} \\ 0 & t<t^{\prime}\end{cases}
$$

therefore the equation (5) takes the following form:

$$
\langle\hat{A}(x, t)\rangle_{t}=\langle A(x, t)\rangle_{0}+L\left(t, t_{0}\right)
$$

where:

$$
L\left(t, t_{0}\right)=\frac{1}{i \hbar} \int_{t_{0}}^{t} d^{\prime} \Theta\left(t-t^{\prime}\right)\left\langle A(x, t) \hat{W}\left(t^{\prime}\right)-\hat{W}\left(t^{\prime}\right) A(x, t)\right\rangle_{0}
$$

and it is called linear response or the response to an external perturbation $W(t)$.

\section{Linear response of the system and Green's functions}

For the analysis of the linear response it is necessary to perform concretization $\hat{W}(t)$. One of the more general forms for Hamiltonian of the external perturbation is [4-7]:

$$
\hat{H}_{\text {int }}\left(t^{\prime}\right)=\int d x^{\prime} \hat{B}\left(x^{\prime}, t^{\prime}\right) \varepsilon\left(x^{\prime}, t^{\prime}\right)
$$

where $\hat{B}\left(x^{\prime}, t^{\prime}\right)$ are the operators of some dynamic variable $B$, and $\varepsilon\left(x^{\prime}, t^{\prime}\right)$-are the functions which do not have the operator structure and are sometimes called C-numbers. As: 


$$
\hat{W}(t)=\exp \left(-\frac{H_{0} t}{i \hbar}\right) \hat{H}_{\text {int }}(t) \exp \left(\frac{H_{0} t}{i \hbar}\right),
$$

on the basis of (8), operator $W\left(t^{\prime}\right)$ will be:

where

$$
\hat{W}\left(t^{\prime}\right)=\int d x^{\prime} B\left(x^{\prime}, t^{\prime}\right) \varepsilon\left(x^{\prime}, t^{\prime}\right)
$$

$$
B\left(x^{\prime}, t^{\prime}\right)=\exp \left(-\frac{H_{0} t}{i \hbar}\right) \hat{B}\left(x^{\prime}, t^{\prime}\right) \exp \left(\frac{H_{0} t}{i \hbar}\right),
$$

is the Schröedinger's operator written in the interaction representation. Combining (10) and (7) one obtains:

where the quantity:

$$
L\left(t, t_{0}\right)=\frac{1}{i \hbar} \int d x^{\prime} \int_{t_{0}}^{t} d^{\prime} \varepsilon\left(x^{\prime}, t^{\prime}\right) G\left(x, x^{\prime} ; t, t^{\prime}\right)
$$

$$
G\left(x, x^{\prime} ; t, t^{\prime}\right) \equiv \Theta\left(t-t^{\prime}\right)\left\langle A(x, t) B\left(x^{\prime}, t^{\prime}\right)-B\left(x^{\prime}, t^{\prime}\right) A(x, t)\right\rangle_{0}
$$

is called two times temperature commutator retarded Green's function. It is the measure of the linear response on some perturbation. It depends on $6 N+2$ variables (two times three spatial and two temporal). If the space is homogenous (no defects, impurities, etc.) then Green's function, as the physical property of that observed system, does not depend on configuration coordinates $x$ and $x^{\prime}$ separately, but rather on their differences $x-x^{\prime}$, so the number of variables is reduced to $3 N+2$. If the original operators do not explicitly depend on time, that is $\hat{A}(x, t) \equiv \hat{A}(x)$ and $\hat{B}(x, t) \equiv \hat{B}(x)$, then Green's function does not depend on time coordinates $t$ and $t^{\prime}$ separately, but rather on their differences $t-t^{\prime}$ as well, thus the total number of variables is reduced to $3 N+1$. In such case Green's function (13) turns into:

$$
\begin{aligned}
G\left(x, x^{\prime} ; t, t^{\prime}\right) \rightarrow & G\left(x-x^{\prime}, t-t^{\prime}\right)= \\
& =\Theta\left(t-t^{\prime}\right)\left[J_{\mathbb{B}}\left(x-x^{\prime}, t-t^{\prime}\right)-J_{B}\left(x-x^{\prime}, t-t^{\prime}\right)\right] .
\end{aligned}
$$

This is Tyablikov's representation of the Green's functions [5,7] and it is different from Zubarev's approach [4,6].

Here are introduced the correlation functions:

$$
\begin{aligned}
& J_{B}\left(x-x^{\prime}, t-t^{\prime}\right)=\left\langle A(x, t) B\left(x^{\prime}, t^{\prime}\right)\right\rangle_{0} ; \\
& J_{B}\left(x-x^{\prime}, t-t^{\prime}\right)=\left\langle B\left(x^{\prime}, t^{\prime}\right) A(x, t)\right\rangle_{0},
\end{aligned}
$$


and they contain all the necessary information on the properties of the observed system. For that particular reason the method of Green's functions has the great importance in theoretical physics of condensed matter [8-10].

If symbolical change of variables is performed: $x \rightarrow \vec{n}$ and $x^{\prime} \rightarrow \vec{m}$, and if we set $t^{\prime}=0$, the equation for the Green's function can be written in the following form:

$$
G_{\vec{n} \vec{m}}(t) \equiv\left\langle A_{\vec{n}}(t) \mid B_{\vec{m}}(0)\right\rangle=\Theta(t)\left\langle\left[A_{\vec{n}}(t) B_{\vec{m}}(0)\right\rangle_{0} .\right.
$$

It is considered that the most frequently used method for the calculation of correlation functions, and thus for the calculation of all relevant properties of the observed system, is certainly the Green's function equation of motion method [10-12]:

$$
\frac{d}{d} G_{\vec{n} \vec{m}}(t)=\frac{d}{d} \Theta(t)\left\langle\left[A_{\vec{n}}(t), B_{\vec{m}}(0)\right\rangle_{0}+\Theta(t)\left\langle\left[\frac{d_{\vec{n}}(t)}{d}, B_{\vec{m}}(0)\right]\right\rangle_{0} \cdot(\right.
$$

By using the Heisenberg's equations of movement for the operators of physical values and fundamental definitions:

$$
\begin{aligned}
i \hbar \frac{d}{d} A(t)=\left[A_{\vec{n}}(t), \hat{H}(t)\right] ; \\
\quad[A, B]=\boldsymbol{B}-B ; \frac{d}{d} \Theta(t)=\delta(t)
\end{aligned}
$$

this expression is reduced to:

$$
i \hbar \frac{d}{t} G_{\vec{n} \vec{m}}(t)=i \hbar \delta(t) C_{\vec{n} \vec{m}}+\left\langle\left[A_{\vec{n}}(t), H(t)\right] B_{\vec{m}}(0)\right\rangle,
$$

where correlation function is $C_{\vec{n} \vec{m}} \equiv\left\langle\left[A_{\vec{n}}(t) B_{\vec{m}}(0)\right]\right\rangle$.

By applying the time-frequency Fourier's transformation:

$$
G_{\vec{n} \vec{m}}(t)=\int^{\infty} d \omega \mathrm{e}^{-i \omega t} G_{\vec{n} \vec{m}}(\omega)
$$

the equation (18) changes to:

$$
\hbar \omega G_{\vec{n} \vec{m}}(\omega)=\frac{i \hbar}{2 \pi} C_{\vec{n} \vec{m}}+\left\langle\left[A_{\vec{n}}(t), H(t)\right] B_{\vec{m}}(0)\right\rangle_{\omega} .
$$

It can be seen that Green's function $G_{\vec{n} \vec{m}}(\omega) \equiv\left\langle A_{\vec{n}}(t) \mid B_{\vec{m}}(0)\right\rangle_{\omega}$ is expressed through new -- higher Green's function $\left\langle\left[A_{\vec{n}}(t), H(t)\right] \mid B_{\vec{m}}(0)\right\rangle_{\omega}$ Higher Green's functions are calculated in the same way as the regular one 
(using the equations of movement), so the endless series is formed, the so called hierarchy of linked equations for the determination of Green's function [10-12]. To calculate the wanted one-particle, and rarely two-particle Green's function, this infinite series must be broken somewhere by using certain, sufficiently justified, approximation [7-9]. The basic calculation problem with Green's functions is to express the new Green's function, with the mentioned approximation, through the initial Green's function and in that way to close the system of equations.

It is interesting to emphasize that Green's functions have a deeper physical meaning. Namely, the real parts of their poles represent the energies of elementary excitations, while the reciprocal values of the imaginary parts of their poles determine the existence times of those excitations [7-10].

Besides that, it is necessary to provide a connection between these Green's functions which, as mentioned before, define all the other physical properties of the observed system. This connection is expressed through the spectral theorem $[4-6,13]$ :

$$
\lim _{\delta \rightarrow+0}\left[G_{\vec{n} \vec{m}}(\omega+i \delta)-G_{\vec{n} \vec{m}}(\omega-i \delta)\right]=\left(\mathrm{e}^{\hbar \omega / \theta}-1\right) J_{B}^{\vec{n} \vec{m}}(\omega)
$$

where $J_{B}^{\vec{n} \vec{m}}(\omega)$ is Fourier's transform of the correlation function $J_{B}^{\vec{n} \vec{m}}(t)$. For $t=0$ the correlation functions given by (2.8) represent the average values of the appropriate operators product.

In theoretical physics Green's functions of various types are used. If averaging is performed with relation to the ground state, they are called Field Green's functions and are used in quantum field theory. If averaging is performed with relation to the statistical ensemble, then they are thermodynamical Green's functions. If they are explicitly time-dependant, then we are dealing with temperature or Matsubara Green's functions [9].

Green's functions are defined in the quantum field theory, where continual variables are mostly used. Their application in solid state physics is enabled by translational invariability of a given crystalline sample [10-12].

Knowing the Green's functions enables one to find the energy of the ground state of the system, spectrum and the type of elementary excitations, following with thermodynamical properties in equilibrium and non-equilibrium states of the observed system [4-6]. Herein we show the application of Green's functions for defining the way of phonon propagation through crystalline structures. 


\section{Calculation of the diffusion tensor of phonon system}

According to Kubo formula $[13,14]$ the diffusion tensor is defined as:

$$
D_{i j}^{f}(k)=\lim _{\delta \rightarrow 0+} \int_{0}^{\infty} d t \mathrm{e}^{-\delta t}\left\langle\hat{v}_{i}(0) \hat{v}_{j}(t)\right\rangle,
$$

where $\hat{v}_{i}$ and $\hat{v}_{j}$ are velocity operators (in Heisenberg representation) of oscillating of molecules in crystal along the crystallographic direction $i, j \in(x, y, z)$, and $\delta$ is perturbation parameter. To find the correlation function that is figuring in the equation for diffusion coefficient, we start from Green's function of momentum--momentum type $\left\langle p_{i}(t) \mid p_{j}(0)\right\rangle$ since $\hat{v}_{i, j} \equiv \hat{p}_{i, j} / m$.

Hamiltonian of the phonon system is given in the form:

$$
\begin{aligned}
H= & \frac{1}{2 M} \sum_{\vec{n}} p_{\vec{n}}{ }^{2}+\frac{C_{H}}{2} \sum_{\vec{n}}\left(u_{\vec{n}}^{2}+u_{\vec{n}-\vec{\lambda}}^{2}-2 u_{\vec{n}} u_{\vec{n}-\vec{\lambda}}\right) \\
& \vec{n} \in\left(n_{x}, n_{y}, n_{z}\right) \quad \mid \vec{\lambda} \models 1
\end{aligned}
$$

where $M$ are molecule masses, $C_{H}$ Hook's stretching constants, $u$ are molecule displacements [15-17]. It should be emphasized that the mentioned Hamiltonian of the ideal phonon structure is given in the harmonic and closest neighbours approximation, while the boundary conditions will be considered in the system of equations for crystalline films Green's function [17-20].

Using the presented procedure for calculation of Green's function, which is in detail explained in our paper [21], one can write the following equation:

$$
\begin{array}{r}
\frac{d}{d}\left\langle p_{f}(t) \mid p_{g}(0)\right\rangle=C_{H}\left[\left\langle u_{f+1}(t) \mid p_{g}(0)\right\rangle+\right. \\
\left.\quad+\left\langle u_{f-1}(t) \mid p_{g}(0)\right\rangle-2\left\langle u_{f}(t) \mid p_{g}(0)\right\rangle\right]
\end{array}
$$

In this equation Green's functions of movement--momentum type appear. When they are calculated, the following equalities are obtained: 


$$
\begin{aligned}
& \frac{d}{d}\left\langle u_{f}(t) \mid p_{g}(0)\right\rangle=i \hbar \delta_{f, g} \delta(t)+\frac{1}{M}\left\langle p_{f}(t) \mid p_{g}(0)\right\rangle ; \\
& \frac{d}{d}\left\langle u_{f+1}(t) \mid p_{g}(0)\right\rangle=i \hbar \delta_{f+1} \delta(t)+\frac{1}{M}\left\langle p_{f+1}(t) \mid p_{g}(0)\right\rangle ; \\
& \frac{d}{d}\left\langle u_{f-1}(t) \mid p_{g}(0)\right\rangle=i \hbar \delta_{f-1} \delta(t)+\frac{1}{M}\left\langle p_{f-1}(t) \mid p_{g}(0)\right\rangle,
\end{aligned}
$$

where $\delta_{f, g}$ and $\delta_{f \pm l g}$ are Kronecker's operators, and $\delta(t)$ is Dirac's delta-function.

If Fourier's transformations of frequency-time type are introduced:

$$
\left\langle a_{f}(t) \mid b_{g}(0)\right\rangle=\int_{-\infty}^{\infty} d \omega \mathrm{e}^{-i \omega t}\left\langle a_{f} \mid b_{g}\right\rangle_{\omega},
$$

and when Fourier image $\left\langle u_{f} \mid p_{g}\right\rangle_{\omega}$ is substituted into equation for $\left\langle p_{f} \mid p_{g}\right\rangle_{\omega}$ with crystalline structures for the case when $f=g$, one finally obtains:

$$
\begin{aligned}
\left\langle p_{f} \mid p_{f}\right\rangle_{\omega} & =\frac{i \hbar C_{H}}{\pi \omega^{2}}+\frac{C_{H}}{M \omega^{2}}\left(2\left\langle p_{f} \mid p_{f}\right\rangle_{\omega}-\right. \\
& \left.-\left\langle p_{f+1} \mid p_{f}\right\rangle_{\omega}-\left\langle p_{f-1} \mid p_{f}\right\rangle_{\omega}\right) .
\end{aligned}
$$

The system of difference equations for Green's functions follows from here:

$$
\left\langle p_{f+1} \mid p_{f}\right\rangle_{\omega}+\left\langle p_{f-1} \mid p_{f}\right\rangle_{\omega}+\left(\frac{M \omega^{2}}{C_{H}}-2\right)\left\langle p_{f} \mid p_{f}\right\rangle_{\omega}=\frac{i \hbar M}{\pi} \text {. }
$$

By solving this system of difference equations we find the Green's functions which figure in it.

The appropriate correlation functions [21] are:

$$
\left\langle p_{f}(t) p_{f}(0)\right\rangle=\frac{\hbar C_{H}}{\omega_{k}}\left(\frac{\mathrm{e}^{-i \omega_{k} t}}{\mathrm{e}^{\hbar \omega_{k} / \theta}-1}-\frac{\mathrm{e}^{i \omega_{k} t}}{\mathrm{e}^{-\hbar \omega_{k} / \theta}-1}\right)
$$

and, if we go back to the formula which defines the diffusion coefficients $D_{j}^{f}(k)$ of the phonon system, one obtains:

$$
D_{i j}^{f}(k)=\lim _{\delta \rightarrow 0+} \frac{\hbar C_{H}}{M^{2} \omega_{k}} \int_{8}^{\infty}\left(\mathrm{e}^{-\delta t} \frac{\mathrm{e}^{-i \omega_{k} t}}{\mathrm{e}^{\hbar \omega_{k} / \theta}-1}-\mathrm{e}^{-\delta t} \frac{\mathrm{e}^{i \omega_{k} t}}{\mathrm{e}^{-\hbar \omega_{k} / \theta}-1}\right) d t,
$$

which finally gives:

$$
D_{i j}^{f}(k)=\left|i \frac{\hbar C_{H}}{M^{2} \omega_{k}^{2}}\right|
$$

[8] NBP • Žurnal za kriminalistiku i pravo 


\section{Results and conclusions}

The results of the calculation conducted here are the following:

The diffusion tensor of phonon system is diagonal, that is $D_{i i}^{f}(k)=\frac{\hbar C_{H}}{M^{2} \omega_{k}^{2}}$.

1) The eigenvalues have higher values for the lower frequencies and are temperature independent.

The last conclusion is very significant because it justifies the macroscopic theories of heat conduction in which it is taken that diffusion coefficient is temperature independent. This fact and the effects that it could cause is very important in the theory of phonon engineering [22-26], especially regarding contemporary nanostructures.

\section{Acknowledgements}

The authors of this paper owe a debt of gratitude to their teacher, mentor and friend, unfortunately - the recently deceased Academician, Prof. Dr. Bratislav S. Tošić. His proper and quality oriented suggestions had the crucial impact on the value and importance of our work.

This paper was in part supported by the Serbian Ministry of Education, Science and Technological Development (Grants: ON-171039 and TR-34019), the Ministry of Science and Technological Development of the Republic of Srpska (Grant: 19/6-020/961-16/15) and the Provincial Secretariat for Higher Education and Scientific Research of Vojvodina (Grand 114-451-2092/2016).

\section{References}

1. Ziman, J. M.; Principles of the Theory of Solids, Cambridge University Press, Cambridge 1999.

2. Teylor, P. L.; Heinonen, O.; A Quantum Approach to Condensed Matter Physics, Cambridge University Press, Cambridge 2002.

3. Kittel, Ch.; Introduction to Solid State Physics, J. Wiley \& Sons, New York 2005.

4. Zubarev, D. N.; Nonequilibrium Statistical Thermodynamics, Nauka, Moskva 1971 - in Russian 
5. Tyablikov, S. V.; Metods of Quantum Theory of Magnetism, Nauka, Moskva 1975 - in Russian

6. Zubarev, D.; Morozov, V.; Repke, G.; Statistical Mechanics of Nonequilibrium Processes, Vol.2, Akademie Verlag, Berlin 1997.

7. Tošić, B. S.; Statistical Physics, Faculty of Sciences, Novi Sad 1978 - in Serbian

8. Ziman, J. M.; Electrons and Phonons: The Theory of Transport Phenomena in Solids, Oxford University Press, New York 2001.

9. Fetter, A. L.; Walecka, J. D.; Quantum Theory of Many-Particle Systems, Dover, New York 2003.

10. Mahan, G. D.; Many-Particle Physics, Springer, Plenum Press, New York 1990.

11. Doniach, S.; Sondheimer, E. H.; Green's Functions for Solid State Physicists, Imperial College, London 2004.

12. Rickayzen, G.; Green's Functions and Condensed Matter, Dover, Mineola 2013.

13. Kubo, R. J.; Statistical-Mechanical Theory of Irreversible Processes. I. General Theory and Simple Applications to Magnetic and Conduction Problems, Phys.Soc.Japan 12, 570-586 (1957).

14. Agranovich, V. M.; Galanin, M. D.; Energy Transport of Electron Excitations in Condensed Environments, Nauka, Moskwa 1978 - in Russian

15. Vragović, I. D.; Fürstenberg, R.; Stojković, S. M.; Šetrajčić, J. P.; Mirjanić, D. Lj.; Phonon Spectra of Quantum Wires, Novi Sad J. Math. 30/3, 185-190 (2000).

16. Jaćimovski, S. K.; Ilić, I. D.; Junger I. K. and Šetrajčić, J. P.; Microtheoretical and Numerical Calculation of Phonon Spectra in Superlattices, Novi Sad J. Math. 31/1, 55-64 (2001).

17. Šetrajčić, J. P.; Jaćimovski, S. K.; Raković, D.; Ilić, D. I.; Phonon Spectra in Crystalline Nanostructures, in "Electrical and Computer Engineering Series: Advances in Simulation, Systems Theory and Systems Engineering", pp.146-151, Eds. N. E. Mastorakis, V. V. Kluev and Đ. Koruga, WSEAS Press, Athens 2003.

18. Sajfert, V. D.; Šetrajčić, J. P.; Jaćimovski, S. K.; Tošić, B. S.; Thermodynamic and Kinetic Properties of Phonons in Cylindrical Quantum Dots, Physica E 353, 479-491 (2005).

19. Šetrajčić, J. P.; Zorić, V. M.; Delić, N. V.; Mirjanić, D. Lj.; Jaćimovski, S. K.; Phonon Participation in Thermodynamics and Superconductive Properties of Thin Ceramic Films, Ch.15, pp. 317-348, In "Thermodynamics", Ed. M. Tadashi, InTech, Vienna 2011. 
20. Šetrajčić, J. P.; Ilić, D. I.; Markoski, B.; Šetrajčić, A. J.; Vučenović, S. M.; Mirjanić, D. Lj.; Škipina, B.; Pelemiš, S. S.; Adapting and Application of the Green's Functions Method onto Research of the Molecular Ultrathin Film Optical Properties, Physica Scripta T 135, 014043: 1-4 (2009).

21. Šetrajčić, J. P.; Jaćimovski S. K. and Vučenović, S. M.; Diffusion of Phonons through (along and across) the Ultrathin Crystalline Films, Physica A 486(5), 839-848 (2017).

22. Cheng. G.; Zeng, T.; Borca-Tasciuc, T.; Song, D.; Phonon Engineering in Nanostructures for Solid-State Energy Conversion, Mat.Sci.Eng. A 292, 155 (2000).

23. Shinde, S. L.; Piekos, E. S.; Sullivan, J. P.; Friedmann, T. A.; Hurley, D. H.; Aubry, S.; Peebles, D. E.; Emerson, J. A.; Phonon Engineering for Nanostructures, Sandia Report, Springfield 2010.

24. Toberer, E. S.; Zevalkink, A.; Snyder, J.; Phonon Engineering through Crystal Chemistry, J.Mater.Chem. 21, 15843 (2011),

25. Šetrajčić, J. P.; Jaćimovski, S. K.; Review of Results of Theoretical Approaches to Phonon Engineering of Thermodynamic Properties for Different Quantum Structures, NBP 20/3, 67 (2015).

26. Sajfert, V. D.; Šetrajčić, J. P.; Jaćimovski, S. K.; Phonon Engineering Theory of Crystalline Nanostructures, Lambert Academ.Publ., Saarbrücken 2015. 


\title{
PROCES DIFUZIJE FONONA KROZ KRISTALNE STRUKTURE
}

\author{
Jovan P. Šetrajčić \\ Prirodno-matematički fakultet Univerziteta u Novom Sadu
}

\section{Stevo K. Jaćimovski}

Kriminalističko-policijska akademija, Beograd

\section{Dušan I. Ilić}

Fakultet tehničkih nauka Univerziteta u Novom Sadu

Sažetak: Umesto uobičajenog pristupa, primenom Grinovih funkcija tipa pomeraj-pomeraj, tenzor difuzije izračunat je primenom Grinovih funkcija tipa impuls-impuls. Ove funkcije figurišu u Kubo formuli koja definiše difuzione osobine sistema. Izračunavanje tenzora difuzije zahteva rešavanje sistema diferencnih jednačina. U radu je pokazano da elementi tenzora difuzije ukazuju na diskretnost zakona disperzije elementarnih pobuđenja, i - što je još značajnije - ne zavise od temperature. Rezultati sprovedenih izračunavanja pokazali su da je tenzor difuzije fononskog podsistema u kristalnim strukturama dijagonalan i da svojstvene vrednosti imaju više vrednosti pri nižim frekvencijama. Navedeni zaključci su od velikog značaja, jer potvrđuju makroskopske teorije toplotnog provođenja koje tvrde da je koeficijent difuzije temperaturski invarijatan. Ova činjenica, kao i posledice koji iz nje mogu proizaći, imaju ogroman potencijalni značaj za primenu fononskog inženjeringa, prvenstveno kod savremenih nanostruktura.

Ključne reči: kristalne strukture, fononi, Grinove funkcije, tenzor difuzije 